\title{
Premature Appearance of Gluconeogenesis and Fatty Acid Oxidation in the Liver of the Postterm Rabbit Fetus
}

\author{
CATHERINE HERBIN, PIERRE-HENRI DUÉE, JEAN-PAUL PÉGORIER, CINTA BLADÉ, \\ CLAUDE KOHL, AND JEAN GIRARD \\ Centre de Recherches sur la Nutrition, CNRS, Meudon-Bellevue, France
}

\begin{abstract}
The metabolic consequences of a prolonged gestation (35 vs 32 days) have been studied in the rabbit fetus. Gestation was prolonged by daily subcutaneous injections of progesterone $\left(1.5 \mathrm{mg} \cdot \mathrm{kg}^{-1}\right)$ from day 28 to 34 . In control animals, progesterone was injected from day 25 or 28 to day 31 of gestation. When the capacities for gluconeogenesis and fatty acid oxidation, measured on isolated hepatocytes, are normally low in the term control fetus and increase only within the first $24 \mathrm{~h}$ after birth, these capacities appear high in the postmature fetus. The rate of glucose production from lactate is 4 -fold higher in the postmature fetus than in the normal term fetus. The rate of ketone body production from oleate is also 5-fold higher in the postmature fetus, which results from a switch on of the partition of oleate into esterification and oxidation: $8 \%$ of $\left[1-{ }^{14} \mathrm{C}\right]$ oleate is oxidized in term fetus hepatocytes, but $34 \%$ in postmature fetus hepatocytes. As a similar rate of lipogenesis takes place in both stages, this metabolic change could be explained by a 5 -fold lower sensitivity of carnitine palmitoyltransferase $I$ to the inhibition by malonyl-coenzyme A. Postmaturity decreases plasma insulin concentrations by $45 \%$ and increases plasma glucagon concentrations by $\mathbf{5 0 \%}$ which, in turn, induces a 3-fold decrease in the plasma insulin:glucagon molar ratio. As previously shown in fasted or diabetic adult rat, this hormonal change might be a likely candidate for an enhancement of gluconeogenic and ketogenic capacity in the liver of the postterm rabbit fetus. (Pediatr Res 23: 224-228, 1988)
\end{abstract}

Abbreviation

CoA, coenzyme A

During pregnancy, the fetus receives a continuous supply of nutrients, principally glucose and amino acids for its growth and its oxidative metabolism which makes unnecessary the development of metabolic pathways as those involved in endogenous glucose production or free fatty acid oxidation (1). Previous studies performed in rabbit hepatocytes have shown that gluconeogenesis from lactate or oleate oxidation and ketogenesis proceed to a very low rate in term fetus and increase during the first day after birth $(2,3)$. The postnatal emergence of hepatic gluconeogenesis and fatty acid oxidation correspond to a shifting of

Received July 31, 1987; accepted October 14, 1987.

Correspondence and reprint requests Pierre-Henri Duée, Centre de Recherches sur la Nutrition, CNRS, 9 rue Jules Hetzel, 92190 Meudon-Bellevue, France.

Supported in part by Grant CRE 867010 from the Institut National de la Santé et de la Recherche Médicale. specific limiting steps that have been well described. The emergence of hepatic gluconeogenesis in the newborn rabbit may result from a rapid fall in hepatic fructose 2,6-bisphosphate concentration (4) and from an increase in the activity of cytosolic phosphoenolpyruvate carboxykinase (2). Moreover, it has been shown that the postnatal increase in mitochondrial adenine nucleotide content stimulates pyruvate carboxylation causing a rapid increase in the rate of hepatic gluconeogenesis $(5,6)$. The development of hepatic fatty acid oxidation in the newborn rabbit is linked to modifications of the channeling of fatty acids in the liver (3) associated with profound changes in the characteristics of carnitine palmitoyltransferase I (7). It has been suggested that the postnatal increase in plasma glucagon concomitantly with the fall in plasma insulin which characterize many species including the rabbit $(1,8)$, are involved in the induction of hepatic gluconeogenesis and ketogenesis $(9,10)$.

Previous observations in the rat have shown that prolongation of gestation for 2 days induces changes in the circulating pancreatic hormone concentrations in the postmature fetus similar to those observed in the term newborn $(11,12)$. Nevertheless, the metabolic consequences of these hormonal alterations in the liver of the postmature fetus have not been investigated.

The purpose herein was to study the changes in pancreatic hormone concentrations in the plasma of postmature rabbit fetus and to measure the capacity for gluconeogenesis and fatty acid oxidation in isolated hepatocytes from postmature fetuses.

\section{MATERIALS AND METHODS}

Animals. Does from the New-Zealand White strain were fed a pelleted laboratory food ad libitum (\% of energy: $33 \%$ protein, $55 \%$ carbohydrate, $12 \%$ fat) and had free access to water. Term in this strain is 32 days postcoitum. Gestation was prolonged by daily subcutaneous injections of progesterone (Roussel Uclaf, Romainville, France, $1.5 \mathrm{mg} \cdot \mathrm{kg}^{-1}$ ) from day 28 to 34 . In preliminary control experiments, progesterone was injected from day 25 or 28 to day 31 of gestation. Fetuses were delivered by cesarean section either in the morning of day 32 (term fetus) or of day 35 (postmature fetus) and weighed. The isolation of hepatocytes or mitochondria was performed within 15 min after delivery or 24 $h$ after birth on day 32 in newborns maintained unfed in an humidified incubator at $36^{\circ} \mathrm{C}(70 \%$ of relative humidity). Because the parameters measured in hepatocytes isolated from control term fetuses (fatty acid oxidation, gluconeogenesis from lactate) are identical whatever the gestational age at the first progesterone injection (day 25 or 28 ), fetuses born from mothers injected from day 28 of gestation were used as control animals.

Blood and liver sampling. Blood from one or two fetuses in each litter was sampled after cutting axillary vessels and was collected in heparinized tubes cooled in ice. Aliquots of whole blood were immediately deproteinized in ice-cold $6 \%(\mathrm{w} / \mathrm{v})$ 
perchloric acid. Glucose, lactate, acetoacetate, and $\beta$-hydroxybutyrate were determined on neutralized perchloric filtrates. Plasma obtained after centrifugation at $4^{\circ} \mathrm{C}$ was stored at $-20^{\circ}$ $\mathrm{C}$ until insulin and glucagon determinations. Livers were removed immediately after blood sampling, frozen in liquid nitrogen, and stored at $-20^{\circ} \mathrm{C}$ until analysis of glycogen and triacylglycerol concentrations.

Isolation and incubation of hepatocytes. Hepatocytes from three to four newborns were prepared by the reverse perfusion technique as described previously (2). Isolated hepatocytes $(5 \times$ $10^{6}$ ) were incubated for $60 \mathrm{~min}$ in a shaking-water bath at $37^{\circ} \mathrm{C}$ in a final volume of $2 \mathrm{ml}$ Krebs Henseleit bicarbonate buffer (pH 7.4). Before sealing, the flaskes were gassed with $\mathrm{O}_{2}: \mathrm{CO}_{2}$ $(19: 1)$ for $30 \mathrm{~s}$.

Measurement of the rate of gluconeogenesis. Hepatocytes were incubated without addition of exogenous substrate for the determination of the rate of endogenous glucose production, or in the presence of lactate or dihydroxyacetone at a final concentration of $10 \mathrm{mmol} /$ liter or of galactose at a final concentration of 5 $\mathrm{mmol} / \mathrm{liter}$. The incubations were ended by adding $0.25 \mathrm{ml}$ perchloric acid $40 \%(\mathrm{v} / \mathrm{v})$. Glucose, lactate, and pyruvate were determined in the neutralized perchloric extracts. Net glucose production for each substrate corresponds to the rate of glucose production measured in the presence of substrate minus the rate of glucose production without the substrate.

Metabolism of $\left[1-{ }^{14}\right.$ C]oleate. Hepatocytes were incubated in the absence of exogenous substrate for the determination of the rate of endogenous ketone body production, or in the presence of $0.35 \mu \mathrm{Ci}$ of $\left[1-{ }^{14} \mathrm{C}\right]$ oleate with oleate $(1 \mathrm{mmol} / \mathrm{liter})$ bound to $2 \%$ dialyzed albumin (fraction $\mathrm{V}$, fatty acid free) plus L-carnitine ( $1 \mathrm{mmol} / \mathrm{liter}$ ). For the measurement of oleate oxidation and ketogenesis, incubations were ended by adding $0.25 \mathrm{ml}$ perchloric acid $(40 \% \mathrm{v} / \mathrm{v})$ as described previously (3). For the study of oleate esterification, incubations were ended by centrifugation for $30 \mathrm{~s}$ at $3000 \times g$ to separate cells from the medium. Cell lipids were extracted by $4 \mathrm{ml}$ of chloroform:methanol $(2: 1 \mathrm{v} / \mathrm{v})$ and an aliquot of this extract was separated by thin-layer chromatography as previously described (3).

Measurement of the rate of lipogenesis. Hepatocytes were preincubated for $30 \mathrm{~min}$ in the absence or in the presence of oleate $(1 \mathrm{mmol} /$ liter $)$ and L-carnitine $(1 \mathrm{mmol} / \mathrm{liter})$ bound to dialyzed albumin. Then, $250 \mu \mathrm{Ci}$ of ${ }^{3} \mathrm{H}_{2} \mathrm{O}$ were added and hepatocytes were further incubated for $30 \mathrm{~min}$. The incubations were ended by centrifugation for $30 \mathrm{~s}$ at $5000 \times g$. Labeled fatty acids were extracted from the cell pellet as described by Stansbie et al. (13).

Isolation and incubation of liver mitochondria. Mitochondria from the livers of one or two newborns were isolated as described previously (7).

Assay of carnitine palmitoyltransferase I. CPT I activity was assayed at $30^{\circ} \mathrm{C}$ as described previously (7). Freshly isolated mitochondria $(0.2 \mathrm{mg} / \mathrm{ml})$ were first preincubated in the presence of $80 \mu \mathrm{mol} /$ liter palmitoyl-CoA bound to $1 \%$ albumin for $3 \mathrm{~min}$ alone or in the presence of raising concentrations of malonylCoA from 0.01 to $150 \mu \mathrm{mol} /$ liter and then further incubated 6 min in the presence of $(2 \mu \mathrm{Ci} / \mu \mathrm{mol})$ [methyl- $\left.{ }^{3} \mathrm{H}\right] \mathrm{L}$-carnitine and L-carnitine $1 \mathrm{mmol} /$ liter. The $\left[{ }^{3} \mathrm{H}\right]$ palmitoylcarnitine formed was measured in the $n$-butanol extract as described by Bremer (14).

Analytical methods. Glucose, lactate, pyruvate, acetoacetate, and $\beta$-hydroxybutyrate were measured by using enzymic methods (15). Plasma insulin was measured by radioimmunoassay as described previously (16). Plasma glucagon was determined using the biodata glucagon kit (Biodata Laboratoire, Serono, Italy). Liver glycogen was assayed using $\alpha$-amylo 1-4, 1-6 glucosidase according to Roehring and Allred (17). Liver triacylglycerol concentrations were determined as described by Le Marchand $e t$ al. (18). Proteins were determined by the method of Lowry et al. (19) using bovine serum albumin as standard.

Chemicals. All enzymes, substrates and cofactors were obtained from Boehringer Corp. (Meylan, France). Fatty acid free albumin, oleate, L-carnitine, and palmitoyl-CoA were purchased from Sigma (St. Louis, MO). ${ }^{3} \mathrm{H}_{2} \mathrm{O},\left[1-{ }^{14} \mathrm{C}\right]$ oleate and [methyl$\left.{ }^{3} \mathrm{H}\right] \mathrm{L}$-carnitine were obtained from the Radiochemical Center Amersham (Bucks, England).

Statistics. Results are expressed as means \pm SEM. Statistical analysis were performed using the Student's unpaired $t$ test (two tailed).

\section{RESULTS}

The prolongation of normal gestation by 3 days produces fetuses with a higher body weight at delivery: $66 \pm 2 \mathrm{~g}(n=20)$ than in term control fetuses: $51 \pm 2 \mathrm{~g}(n=16)$ without alteration in the number of fetuses per litter (seven to nine). Fetal blood and liver parameters and the changes associated with prolonged gestation are shown in Table 1. In postmature fetuses, the liver glycogen and triacylglycerol concentrations are significantly decreased, by 60 and $40 \%$, respectively. Blood glucose and ketone body concentrations are not different in both groups. In contrast, blood lactate concentration, which is already high in term fetuses, further increases $(+22 \%)$ in postmature fetuses. Postmaturity is associated with a decrease in plasma insulin level and an increase in plasma glucagon level which result in a 3-fold decrease in the plasma insulin:glucagon molar ratio.

As shown in Table 2, the rates of endogenous glucose production in hepatocytes isolated from rabbit fetus depend on the gestation length. In hepatocytes from term fetuses, the rate of endogenous glucose production is high and markedly decreases in hepatocytes isolated $24 \mathrm{~h}$ after birth. In contrast, the rate of endogenous glucose production in postmature fetus is much lower. The net production of glucose from lactate or dihydroxyacetone is very low in fetal hepatocytes isolated after a normal gestation and it increases 6-fold during the first $24 \mathrm{~h}$ after birth. In contrast, gluconeogenesis from galactose is already well developed in term fetus. The rates of gluconeogenesis from dihydroxyacetone or galactose in hepatocytes isolated from postmature fetus are very similar to the rates measured in 24-h-old newborns, whereas the rate of gluconeogenesis from lactate remains slightly lower than the value obtained in 24-h-old newborn hepatocytes.

Table 1. Effect of postmaturity on rabbit fetal liver glycogen and triglyceride concentrations, and metabolite or pancreatic hormone concentrations*

\begin{tabular}{lcc}
\hline & Term fetus & Postmature fetus \\
\hline Liver energy stores $(\mathrm{mg} / \mathrm{g})$ & & \\
$\quad$ Glycogen & $37 \pm 5$ & $14 \pm 3 \dagger$ \\
Triacylglycerol & $115 \pm 16$ & $68 \pm 8 \dagger$ \\
& & \\
Blood metabolites (mmol/liter) & & \\
Glucose & $3.93 \pm 0.17$ & $3.37 \pm 0.40$ \\
Lactate & $6.24 \pm 0.38$ & $8.10 \pm 0.40 \dagger$ \\
Total ketone bodies & $0.08 \pm 0.01$ & $0.14 \pm 0.02$ \\
& & \\
Plasma hormones & & \\
Insulin $(\mu \mathrm{U} / \mathrm{ml})$ & $83 \pm 9$ & $46 \pm 5 \dagger$ \\
Glucagon $(\mathrm{pg} / \mathrm{ml})$ & $193 \pm 28$ & $288 \pm 30 \ddagger$ \\
Molar ratio $\mathrm{I}: \mathrm{G}$ & $11.1 \pm 2.2$ & $3.9 \pm 0.4 \dagger$ \\
\hline
\end{tabular}

* Liver from term fetus ( 32 days) or postmature fetus ( 35 days) were removed and immediately stored at $-20^{\circ} \mathrm{C}$ until assay. Blood of one or two fetuses per litter was immediately sampled from axillary vessels. Glucose, total ketone body (acetoacetate $+\beta$-hydroxybutyrate) and lactate concentrations were assayed on the whole blood, while insulin and glucagon were determined on plasma fraction. Values are means \pm SEM of 8-16 samples (blood or liver) performed in duplicate.

$\dagger p<0.01$ when compared with term fetus.

$\ddagger p<0.05$ when compared with term fetus. 
Table 2. Effect of postmaturity on endogenous glucose production and gluconeogenesis from lactate, dihydroxyacetone, or galactose in isolated hepatocytes from term fetus (32 days) postmature fetus (35 days) or 24-h-old rabbit born on day 32 of gestation*

\begin{tabular}{|c|c|c|c|c|}
\hline \multirow[b]{2}{*}{ Animals } & \multirow{2}{*}{$\begin{array}{l}\text { Endogenous } \\
\text { glucose production }\end{array}$} & \multicolumn{3}{|c|}{ Net glucose production $\left(\mathrm{nmol} \cdot \mathrm{h}^{-1} \cdot 10^{6}\right.$ cells $\left.\mathrm{s}^{-1}\right)$ from } \\
\hline & & Lactate & Dihydroxyacetone & Galactose \\
\hline Term fetus & $361 \pm 58$ & $30 \pm 13$ & $32 \pm 8$ & $150 \pm 21$ \\
\hline 24-h-old newborn & $18 \pm 4 \dagger$ & $196 \pm 15 \dagger$ & $191 \pm 19 \dagger$ & $240 \pm 41 \ddagger$ \\
\hline Postmature fetus & $87 \pm 24 \dagger$ & $114 \pm 15 \dagger$ & $221 \pm 22 \dagger$ & $243 \pm 28+$ \\
\hline
\end{tabular}

${ }^{*}$ Hepatocytes were incubated for $1 \mathrm{~h}$ at $37^{\circ} \mathrm{C}$ in the absence or in the presence of lactate $10 \mathrm{mM}$, dihydroxyacetone $10 \mathrm{mM}$, or galactose $5 \mathrm{mM}$. Values are means \pm SEM of six experiments performed in duplicate. Net glucose production is obtained by substracting endogenous glucose production.

$\dagger p<0.01$ when compared with term fetus.

$\ddagger p<0.05$ when compared with term fetus.

The rates of lactate plus pyruvate production from dihydroxyacetone in isolated hepatocytes have also been measured. The apparent amount of dihydroxyacetone metabolized is 3-fold higher in postmature than in term fetus (Table 3). Furthermore, the rate of lactate plus pyruvate production from dihydroxyacetone, as expressed in percentage of the amount of dihydroxyacetone metabolized, is higher in normal term fetus whereas the relative rate of glucose production predominates in postmature fetus. It is noteworthy that the endogenous production of lactate plus pyruvate (i.e. without addition of exogenous precursor) is higher in hepatocytes from term fetus $\left(303 \pm 71 \mathrm{nmol} \cdot \mathrm{h}^{-1} \cdot 10^{6}\right.$ cells $\left.^{-1}, n=8\right)$ than in postmature fetus $\left(52 \pm 15 \mathrm{nmol} \cdot \mathrm{h}^{-1} \cdot 10^{6}\right.$ cells $^{-1}, n=9$ ).

As shown in Table 4, the rates of ketone body production from endogenous sources or from oleate are very low in hepatocytes isolated from term fetus and markedly increase within the first day after birth. The rate of hepatic lipogenesis decreases by $95 \%$ between birth and $24 \mathrm{~h}$ after birth. In postmature fetus, the rate of endogenous ketogenesis or the rate of ketogenesis in the presence of oleate is 4- to 5-fold higher than in the term fetus. However, this enhanced capacity for ketogenesis remains slightly lower than the capacity measured in hepatocytes from 24-h-old newborns. It is noteworthy that this increased capacity for ketogenesis in hepatocytes from postmature fetuses is observed despite a significant higher rate of lipogenesis measured from endogenous sources or in the presence of oleate (Table 4).

The metabolic fate of $\left[1-{ }^{14} \mathrm{C}\right]$ oleate in the presence of exogenous oleate $(1 \mathrm{mmol} / \mathrm{liter})$ is presented in Table 5 . Total $\left[1-{ }^{14} \mathrm{C}\right]$ oleate metabolized is similar both in term and postmature fetuses and in 24-h-old rabbits allowing comparisons of the metabolic distribution of labeled oleate into $\mathrm{CO}_{2}$, acid-soluble products, or triacylglycerols. In term fetus, only $8 \%$ of $\left[1-{ }^{14} \mathrm{C}\right]$ oleate is oxidized while $92 \%$ is esterified. This distribution is profoundly modified in 24-h-old newborn where oleate oxidation is increased 6-fold and oleate esterification is decreased by $40 \%$. This metabolic distribution is also modified in postmature fetus inasmuch as oleate oxidation is increased 4-fold and oleate esterification is decreased by $26 \%$, values slightly lower than the corresponding values observed in 24-h-old newborn hepatocytes.

The activity of CPT I and its inhibition by malonyl-CoA have been determined in freshly isolated mitochondria (Table 6). In all experiments, the CPT I activity is completely inhibited by a high concentration of malonyl-CoA $(0.15 \mathrm{mmol} /$ liter $)$, suggesting that the activity of CPT II does not interfere with the measurement of CPT I activity. CPT I activity is similar in term or postmature fetus but is lower than in liver mitochondria of 24h-old newborn rabbit. The concentration of malonyl-CoA necessary to suppress the activity of CPT I by $50 \%\left(\mathrm{IC}_{50}\right)$ is 30 -fold lower in term fetus than in 24-h-old newborn. Nevertheless $\mathrm{IC}_{50}$ for malonyl-CoA increases 4-fold in mitochondria of postmature fetus compared with term fetus.

\section{DISCUSSION}

The present data demonstrate that the capacities for hepatic gluconeogenesis and fatty acid oxidation are significantly in-
Table 3. Rates of glucose and lactate + pyruvate production from dihydroxyacetone in isolated hepatocytes from term fetus (32 days) or postmature rabbit fetus (35 days)*

\begin{tabular}{lcc}
\hline & Term fetus & Postmature fetus \\
\hline $\begin{array}{l}\text { Amount of dihydroxyacetone } \\
\text { metabolized } \dagger\left(\mathrm{nmol} \cdot \mathrm{h}^{-1} \cdot 10^{6}\right.\end{array}$ & $219 \pm 77$ & $696 \pm 64 \ddagger$ \\
$\begin{array}{l}\text { cells }{ }^{-1} \text { ) } \\
\text { \% glucose }\end{array}$ & $31 \pm 6$ & $66 \pm 2 \ddagger$ \\
\% lactate + pyruvate & $69 \pm 6$ & $34 \pm 2 \ddagger$ \\
\hline
\end{tabular}

* Hepatocytes were incubated for $1 \mathrm{~h}$ at $37^{\circ} \mathrm{C}$ in the presence of dihydroxyacetone $10 \mathrm{mM}$. Values are means $\pm \mathrm{SEM}$ of six experiments performed in duplicate.

$\dagger$ Calculated as $\left[2 \times\left(\right.\right.$ glucose produced $\cdot \mathrm{h}^{-1} \cdot 10^{6}$ cells $\left.^{-1}\right)+($ lactate + pyruvate produced $\left.\left.\cdot \mathrm{h} \cdot{ }^{-1} 10^{6} \mathrm{cells}^{-1}\right)\right]$.

$\ddagger p<0.01$ when compared with term fetus.

Table 4. Rate of ketone body production and lipogenesis in isolated hepatocytes from term (32 days) or postmature fetus (35 days) and 24-h-old rabbit born on day 32 of gestation*

\begin{tabular}{|c|c|c|c|c|}
\hline \multirow[b]{2}{*}{ Animals } & \multicolumn{2}{|c|}{$\begin{array}{c}\text { Ketogenesis } \\
\left(\mathrm{nmol} \cdot \mathrm{h}^{-1} \cdot 10^{6} \mathrm{cells}^{-1}\right)\end{array}$} & \multicolumn{2}{|c|}{$\begin{array}{c}\text { Lipogenesis } \\
\left(\mathrm{nmol} \cdot 30 \mathrm{~min}^{-1} \cdot 10^{6}\right. \\
\left.\text { cells }^{-1}\right)\end{array}$} \\
\hline & Endogenous & + Oleate & Endogenous & + Oleate \\
\hline Term fetus & $18 \pm 12$ & $26 \pm 9$ & $16 \pm 1$ & $8 \pm 3$ \\
\hline 24-h-old newborn & $206 \pm 9 \dagger$ & $236 \pm 18 \dagger$ & $1 \pm 1 \dagger$ & Undetectable \\
\hline Postmature fetus & $68 \pm 11 \ddagger$ & $138 \pm 8 \dagger$ & $8 \pm 1 \dagger$ & $9 \pm 1$ \\
\hline
\end{tabular}

* Hepatocytes were incubated for $1 \mathrm{~h}$ at $37^{\circ} \mathrm{C}$ in the absence or in the presence of oleate $1 \mathrm{mM}+$ carnitine $1 \mathrm{mM}$. Lipogenesis was measured from tritiated water $(250 \mu \mathrm{Ci} /$ flask $)$ added at $30 \mathrm{~min}$. Values are means \pm SEM of six experiments performed in duplicate.

$\dagger p<0.01$ when compared with term fetus.

$\ddagger p<0.05$ when compared with term fetus.

creased during postmaturity in the rabbit fetus, whereas these capacities are normally low in the term fetus and increase only within the first $24 \mathrm{~h}$ after birth $(2,3)$. As gestation was prolonged in the rabbit by daily injections of progesterone, it was necessary to discard an eventual effect of this hormone on the fetal liver metabolism. Term control fetuses were obtained from mother injected with progesterone from the same stage of gestation, i.e. during 4 days before normal term. In these term fetuses, hepatic glycogen and triglyceride concentrations are high as previously reported $(3,8)$. Term fetuses also exhibit high plasma insulin and low plasma glucagon levels as already shown (8). Moreover, despite the progesterone treatment undergone by the doe, the metabolic capacity of the liver of term fetus is unaffected. Active glycolysis and lipogenesis are concomitant with a low capacity for gluconeogenesis and for fatty acid oxidation. Moreover, term control fetuses obtained from mother injected with progesterone during an identical period of 7 days (i.e. from day 25 to 31 ) are also characterized by a low hepatic capacity for gluconeogenesis and for fatty acid oxidation (data not shown). 
Table 5. Effect of postmaturity on $\left[1 \mathrm{I}^{14} \mathrm{C}\right] \mathrm{oleate}$ metabolism in isolated hepatocytes from term (32 days) or postmature fetus (35 days) and 24-h-old rabbit born on day 32 of gestation*

\begin{tabular}{ccccc}
\hline & \multirow{2}{*}{$\begin{array}{c}{\left[{ }^{14} \mathrm{C}\right] \text { oleate metabolized }} \\
\left(\mathrm{dpm} \cdot 10^{3} \cdot \mathrm{h}^{-1} \cdot 10^{6}\right.\end{array}$} & \multicolumn{3}{c}{$\begin{array}{c}\text { Metabolic distribution of } \\
{\left[1{ }^{14} \mathrm{C}\right] \text { oleate metabolized (\%) }}\end{array}$} \\
\cline { 3 - 5 } Animals & $29.2 \pm 4.4$ & $\mathrm{CO}_{2}$ & Acid-soluble products & Triacylglycerols \\
\hline Term fetus & $29.8 \pm 3.8$ & $3.2 \pm 0.4$ & $4.8 \pm 1.9$ & $92.0 \pm 2.3$ \\
24-h-old newborn & $31.6 \pm 1.6$ & $2.2 \pm 0.4$ & $45.0 \pm 3.6 \dagger$ & $52.8 \pm 4.0 \dagger$ \\
Postmature fetus & $6.4 \pm 0.7 \dagger$ & $27.7 \pm 1.9 \dagger$ & $65.9 \pm 2.1 \dagger$ \\
\hline
\end{tabular}

* Hepatocytes were incubated for $1 \mathrm{~h}$ at $37^{\circ} \mathrm{C}$ in the presence of $\left[1-{ }^{14} \mathrm{C}\right]$ oleate $1 \mathrm{mM}(0.35 \mu \mathrm{Ci} /$ flask $)$ bound to $2 \%$ fat-free albumin. Carnitine 1 $\mathrm{mM}$ was added in each experiment. The term "oleate metabolized" represents the sum of dpm recovered in each fraction, i.e. acid-soluble products, $\mathrm{CO}_{2}$ and triacylglycerols. Values are mean \pm SEM of six experiments performed in duplicate.

$\dagger p<0.01$ when compared with term fetus.

Table 6. Effect of postmaturity on hepatic carnitine palmitoyltransferase I (CPT I) activity and sensitivity to malonyl-CoA*

\begin{tabular}{llc}
\hline \multicolumn{1}{c}{ Animals } & $\begin{array}{c}\text { CPT I activity } \\
{\left[\mathrm{nmol} \cdot \mathrm{min}^{-1}\right.} \\
\left..(\mathrm{mg} \text { protein })^{-1}\right]\end{array}$ & $\begin{array}{c}\mathrm{IC}_{50} \text { for inhibition } \\
\text { by malonyl-CoA } \\
(\mu \mathrm{M})\end{array}$ \\
\hline Term fetus & $0.89 \pm 0.13$ & $0.03 \pm 0.01$ \\
24-h-old newborn & $1.87 \pm 0.13 \dagger$ & $0.75 \pm 0.10 \ddagger$ \\
Postmature fetus & $0.96 \pm 0.07$ & $0.12 \pm 0.02 \ddagger$ \\
\hline
\end{tabular}

* Liver mitochondria were isolated from term (32 days) or postmature fetus ( 35 days) and from 24-h-old rabbit born on day 32 of gestation. CPT I activity was measured in the presence of palmitoyl-CoA $80 \mu \mathrm{M}$ and $\left[\right.$ methyl $\left.-{ }^{3} \mathrm{H}\right]$ carnitine $1 \mathrm{mM}(2 \mu \mathrm{Ci} / \mu \mathrm{mol})$. The term " $\mathrm{IC}_{50}$ " refers to the concentration of malonyl-CoA giving $50 \%$ inhibition of CPT I activity. Values are means \pm SEM of six determinations performed in duplicate.

$\dagger p<0.05$ when compared with term fetus.

$\ddagger p<0.01$ when compared with term fetus.

These metabolic characteristics of the fetal liver are profoundly modified during postmaturity. Hepatocytes isolated from rabbit postmature fetus display high rates of glucose production from various substrates. Inasmuch as lactate, dihydroxyacetone, and galactose enter the gluconeogenic pathway at different levels, this study allows to check the rate-limiting steps in the development of this metabolic pathway in the postmature rabbit (4). With galactose as a substrate, a maximal rate of glucose production, when compared with $24-\mathrm{h}$-old newborns, is present in the hepatocytes of postmature fetus, which underlines that the futile cycle between glucose-6-phosphate and glucose is displaced toward glucose synthesis. The rates of glucose and of lactate plus pyruvate production from dihydroxyacetone may reflect the apparent amount of dihydroxyacetone used as $\mathrm{C}_{3}$ units and its partitioning into the pathways of gluconeogenesis and glycolysis. The present data suggest that the high rate of glucose production from dihydroxyacetone in the postmature fetus arises primarily from a reduced glycolytic flux through inhibition of phosphofructokinase and pyruvate kinase. A similar shift of glycolysis and gluconeogenesis is also achieved in hepatocytes isolated from 24$\mathrm{h}$-old newborn rabbits. This is consistent with a decrease in the hepatic fructose 2,6-bisphosphate concentration (4), secondary to the drop in the hepatic glycogen concentration (Tables 1 and 2). Although the maximal rate of glucose production in the presence of lactate is not yet reached in the hepatocytes isolated from postmature fetus, the data show a high capacity for gluconeogenesis from this precursor which enters the pathway below phosphoenolpyruvate (Table 2), suggesting a high flux through cytosolic phosphoenolpyruvate carboxykinase (2). In agreement with this, the activity of cytosolic phosphoenolpyruvate carboxykinase is markedly increased in the liver of postmature rat fetus $(20-23)$. However, the fact that the rate of glucose production from lactate is not maximal in the postmature fetus could be due to a lower tissue oxygenation as suggested by other experiments $(5,6,24)$.
The rates of ketogenesis from endogenous sources or from oleate are markedly increased in the hepatocytes isolated from postmature rabbit fetus but did not reach the maximal capacity observed in 24-h-old newborn hepatocytes. This result does not agree with previous data obtained in liver slices of the postmature rabbit fetus showing similar rates of ketone body production from palmitate to the term fetus (25). The emergence of ketogenic capacity in the liver of postmature fetus corresponds to an increased fatty acid oxidation at the expense of fatty acid esterification. Postmaturity induces in the fetal liver a maturation of the fatty acid oxidation pathway that normally appears few hours after birth in the term fetus (3). Such a reciprocal relationship between esterification and oxidation of long-chain fatty acids has also been observed in the adult rat during the fed-starved transition and it seems now well established that the principal site of control of hepatic fatty acid oxidation is located at the level of the carnitine palmitoyltransferase I, which catalyses the entry of fatty acids into mitochondria $(10,26,27)$. More precisely, it has been shown that malonyl-CoA, the first committed intermediate in the conversion of carbohydrate to fat, is a potent inhibitor for carnitine palmitoyltransferase I (28). Low malonyl-CoA concentrations are probably present in the liver of postmature fetus as suggested by the low hepatic glycogen concentration and the low rates of endogenous glycolysis and lipogenesis. This decrease in lipogenic capacity is likely the consequence of the fall in lipogenic enzyme activities because addition of lactate plus pyruvate to isolated hepatocytes from postmature rabbit fetus fails to increase the rate of lipogenesis (data not shown). Nevertheless, the difference in the rate of lipogenesis between term and postmature fetus cannot explain the large increase in ketone body production in the presence of oleate because it does not further decrease the rate of lipogenesis in the postmature fetus (see Table 4). The decrease in the sensitivity of carnitine palmitoyltransferase I to malonyl-CoA in the liver mitochondria of postmature fetus could contribute to the increased capacity for fatty acid oxidation, as it occurred after birth (7) or in adult rat during starvation (26, 27). Now, the present experiments underline that postmature rabbit fetuses continue to grow during a 3-day period after normal term without marked change in the fetal mortality. As previously shown in this species (29-31) or in the rat $(11,32,33)$ this suggests that postmature fetus is in the fed state and that the placental transfer of nutrients and oxygen is sufficient to sustain fetal growth. Recently, a significant increase in the coefficient of oxygen and glucose extraction has been reported in the postterm rabbit (31). However, a lower placental transfer of fatty acids in the postterm rabbit cannot be excluded, as suggested by other data (34-36).

Postmaturity induces clear-cut changes in the concentrations of plasma insulin and glucagon which leads to a lower insulin:glucagon molar ratio in the postmature rabbit fetus. This change in fetal hormonal environment extends previous observations performed in the rat $(11,20,21)$. These hormonal changes during postmaturity are similar, although less pronounced, than those occurring during the postnatal period in the rabbit (8). In adult rats, metabolic states (starvation, diabetes) 
associated with a low plasma insulin:glucagon ratio or glucagon treatment induce a liver glycogen depletion and high rates of gluconeogenesis from lactate or dihydroxyacetone (37). Moreover, it has been shown that injection of glucagon or cAMP to fetal rats in utero causes a marked induction of mRNA for phosphoenolpyruvate carboxykinase which suggests a regulation of phosphoenolpyruvate carboxykinase synthesis by this hormone (9). Conversely, newborn rats of diabetic mothers exhibit a high plasma insulin:glucagon ratio associated with an impaired development of gluconeogenesis after birth $(38,39)$. Similarly, a decrease in the plasma insulin:glucagon molar ratio must favor a low lipogenic rate and a high rate of fatty acid oxidation $(25$, 40-42). Moreover, recent data suggest that glucagon stimulates ketogenesis by early activation of the activity of carnitine palmitoyltransferase I probably by phosphorylation through a cAMP-dependent protein kinase $(43,44)$. The factors responsible for the changes in plasma pancreatic hormones in the postmature rabbit fetus are unknown. However, a low plasma insulin:glucagon molar ratio might be a likely candidate for an enhancement of gluconeogenic and ketogenic capacity in fetal rabbit liver during postmaturity.

Acknowledgments. The authors thank B. Morel (Institut National de la Recherche Agronomique, Jouy-en-Josas) and G. Orain for their assistance in taking care of pregnant rabbits and I. Coquelet and M. Fernandez for the careful preparation of the manuscript.

\section{REFERENCES}

1. Girard J, Ferré P 1982 Metabolic and hormonal changes around birth. In: Jones CT (ed) The Biochemical Development of the Fetus and Neonate. Elsevier, Amsterdam, pp 517-541

2. El Manoubi L, Callikan S, Duée P-H, Ferré P, Girard J 1983 Development and regulation of gluconeogenesis in isolated hepatocytes from the rabbit. Crucial roles of cytosolic phosphoenolpyruvate carboxykinase and fatty acid oxidation. Am J Physiol 244:E24-E30

3. Duée P-H, Pégorier J-P, El Manoubi L, Herbin C, Kohl C, Girard J 1985 Hepatic triglyceride hydrolysis and development of ketogenesis in the rabbit. Am J Physiol 249:E478-E484

4. Duée P-H, Pégorier J-P, El Manoubi L, Ferré P, Bois-Joyeux B, Girard J 1986 Development of gluconeogenesis from different substrates in newborn rabbit hepatocytes. J Dev Physiol 8:387-394

5. Brennan WA, Aprille JR 1984 Regulation of hepatic gluconeogenesis by rapid compartmentation of mitochondrial adenine nucleotides in the newborn rabbit. Comp Biochem Physiol 77:35-39

6. Brennan WA, Aprille JR 1985 Regulation of hepatic gluconeogenesis in newborn rabbit: controlling factors in presuckling period. Am J Physiol 249:E498-E505

7. Herbin C, Pégorier J-P, Duée P-H, Kohl C, Girard J 1987 Regulation of fatty acid oxidation in isolated hepatocytes and liver mitochondria from newborn rabbits. Eur J Biochem 165:201-207

8. Callikan S, Ferré P, Pégorier J-P, Girard J, Marliss EB, Assan R 1979 Fuel metabolism in fasted newborn rabbits. J Dev Physiol 1:267-281

9. Girard J 1986 Gluconeogenesis in late fetal and early neonatal life. Biol Neonate 50:237-258

10. Girard J, Malewiak MI 1986 Fatty acid oxidation and ketogenesis in isolated hepatocytes. In: Guillouzo A, Guillouzo C (eds) Isolated and Cultured Hepatocytes. John Libbey Eurotext Ltd., London, pp 87-112

11. Portha B, Rosselin G, Picon L 1976 Postmaturity in the rat: impairement of insulin, glucagon and glycogen stores. Diabetologia 12:429-436

12. Portha B, Picon L, Rosselin G 1978 Postmaturity in the rat: high levels of glucagon in the plasma of the foetus and neonate. J Endocrinol 77:153-154

13. Stansbie D, Brownsey RW, Crettaz M, Denton RM 1976 Acute effects in vivo of anti-insulin serum on rates of fatty acid synthesis and activities of acetyl$\mathrm{CoA}$ carboxylase and pyruvate dehydrogenase in liver and epididymal adipose tissue of fed rats. Biochem J 160:413-416

14. Bremer J 1981 The effect of fasting on the activity of liver carnitine palmitoyltransferase and its inhibition by malonyl-CoA. Biochim Biophys Acta 665:628-631
15. Bergmeyer HU 1974 Methods of Enzymatic Analysis. Academic Press, New York

16. Girard JR, Cuendet GS, Marliss EB, Kervran A, Rieutort M, Assan R 1973 Fuels, hormones and liver metabolism at term and during the early postnatal period in the rat. J Clin Invest 52:3190-3200

17. Roehring KL, Allred JB 1974 Direct enzymatic procedure for the determination of liver glycogen. Anal Biochem 58:414-421

18. Le Marchand Y, Singh A, Assimacopoulos-Jeannet F, Orci L, Rouiller C, Jeanrenaud B 1973 A role for the microtubular system in the release of very low density lipoproteins by perfused mouse liver. J Biol Chem 248:68626870

19. Lowry OH, Rosebrough NJ, Lewis Farr A, Randall RJ 1951 Protein measurement with the folin phenol reagent. J Biol Chem 193:265-275

20. Girard JR, Ferré P, Kervran A, Pégorier J-P, Assan R 1977 Role of insulin/ glucagon ratio in the changes of hepatic metabolism during development in the rat. In: Foa PP, Bajaj JS, Foa NL (eds) Glucagon, Its Role in Physiology and Clinical Medieine. Excerpta Medica; Amsterdam, pp 563-581

21. Ktorza A, Girard JR, Kinebanyan MF, Picon L 1981 Hyperglycaemia induced by glucose infusion in the unrestrained pregnant rat during the last three days of gestation: metabolic and hormonal changes in the mother and the fetuses. Diabetologia 21:569-574

22. Portha B, Le Provost E, Picon L, Rosselin G 1978 Postmaturity in the rat: phosphorylase, glucose-6-phosphatase and phosphoenolpyruvate carboxykinase activities in the fetal liver. Horm Metab Res 10:141-144

23. Le Provost E, Portha B, Cros JC, Picon L 1980 Postmaturity in the rat: glucose metabolism in the fetus and the neonate. Pediatr Res 14:793-798

24. Aprille JR, Nosek MT 1987 Neonatal hypoxia or maternal diabetes delays postnatal development of liver mitochondria. Pediatr Res 21:266-269

25. Masse D, Roux JF, Harlow A, Shapiro M 1980 In vitro palmitate and glucose metabolism in the postmature fetus. Am J Obstet Gynecol 136:505-508

26. Zammit VA 1984 Mechanisms of regulation of the partition of fatty acids between oxidation and esterification in the liver. Prog Lipid Res 33:39-67

27. Foster DW 1984 From glycogen to ketones and back. Diabetes 33:1188-1199

28. McGarry JD, Foster DW 1980 Regulation of hepatic fatty acid oxidation and ketone body production. Ann Rev Biochem 49:395-420

29. Roux J-F, Romney SL, Dinnerstein A 1964 Environmental and aging effects of postmaturity on fetal development and carbohydrate metabolism. Am $\mathbf{J}$ Obstet Gynecol 90:546-553

30. Shapiro MI, Roux JF 1977 Lipid transport and metabolism in the post term rabbit. Am J Obstet Gynecol 129:171-177

31. Jones RO, Murray RD, Meschia G, Battaglia FC 1987 Metabolic quotients and oxygen extraction acorss the uterus of the post term pregnant rabbit under chronic steady state conditions. Biol Neonate 51:24-30

32. Rosso P 1976 Placental transfer of $\alpha$-amino isobutyric acid and glucose near term and in progesterone-induced prolonged gestation in the rat. Biol Neonate 30:163-168

33. Caswell AM, Higham FC, Bailey E 1983 Hepatic lipogenesis and ketogenesis in the mother and fetus during postmaturity in the rat. J Dev Physiol 5:299305

34. Shapiro MI, Roux JF, Harlow A, Masse D 1979 Placental uptake and transfer of lipid in the post-term rabbit. Am J Obstet Gynecol 133:713-717

35. Harlow AC, Roux JF, Shapiro MI 1980 Plasma glucose, cholesterol, triglyceride, and glycerol concentrations in the postmature rabbit. Am J Obstet Gynecol 136:500-504

36. Harding PGR 1970 Chronic placental insufficiency. An experimental model. Am J Obstet Gynecol 106:857-864

37. Hers HG, Hue L 1983 Gluconeogenesis and related aspects of glycolysis. Ann Rev Biochem 52:617-653

38. Cuezva JM, Burkett ES, Kerr DS, Rodman HM, Patel MS 1982 The newborn of diabetic rat. I. Hormonal and metabolic changes in the postnatal period. Pediatr Res 16:632-637

39. Cuezva JM, Chitra CI, Patel MS 1982 The newborn of diabetic rat. II. Impaired gluconeogenesis in the postnatal period. Pediatr Res 16:638-643

40. Bremer J, Osmundsen H 1984 Fatty acid oxidation and its regulation. In: Numa S (ed) Fatty Acid Metabolism and Its Regulation. Elsevier Scientific Publications B.V., Amsterdam, pp 113-154

41. Cook GA, Nielsen RC, Hawkins RA, Mehlman MA, Lakshman MR, Veech RL 1977 Effect of glucagon on hepatic malonyl-CoA concentration and on lipid synthesis. J Biol Chem 252:4421-4424

42. Agius L, Chowdhury MH, Alberti KGMM 1986 Regulation of ketogenesis, gluconeogenesis and the mitochondrial redox state by dexamethasone in hepatocyte monolayer cultures. Biochem J 239:593-601

43. Harano Y, Kosugi K, Kashiwagi A, Nakano T, Hidaka H, Shiegeta Y 1982 Regulatory mechanism of ketogenesis by glucagon and insulin in isolated and cultured hepatocytes. J Biochem 91:1739-1748

44. Harano Y, Kashiwagi A, Kojima H, Suzuki M, Hashimoto T, Shigeta Y 1985 Phosphorylation of carnitine palmitoyltransferase and activation by glucagon in isolated rat hepatocytes. FEBS Lett 188:267-272 